\title{
Assessment of Hearing Status by Pure Tone Audiogram-An Institutional Study
}

\author{
Ganesh Kumar Balasubramanian, Ramanathan Thirunavukkarasu, \\ Ramesh Babu Kalyanasundaram, Gitanjali Narendran \\ Thanjavur Medical College, Thanjavur, India \\ Email: drganeshkumarb@gmail.com
}

Received 24 July 2015; accepted 26 September 2015; published 29 September 2015

Copyright (C) 2015 by authors and Scientific Research Publishing Inc.

This work is licensed under the Creative Commons Attribution International License (CC BY). http://creativecommons.org/licenses/by/4.0/

c) (i) Open Access

\begin{abstract}
Aim: To assess the hearing status of the study subjects in terms of degree and type of hearing loss, and establish the burden of this disability in the society. Materials and methods: This is a prospective study conducted in patients who attend our OPD. After an otorhinolaryngeal examination, all the patients were subjected to pure tone audiometry using MAICA-MA52 audiometer. Results: Our study comprises 1012 males (64\%) and 563 females (36\%). Out of this, about 15\% have conductive deafness and $42 \%$ have sensorineural hearing loss. About 29\% suffer from mild hearing loss, $26 \%$ moderate and $11 \%$ severe hearing loss. The alarming information is that about $5 \%$ have total hearing loss of Sudden Sensorineural type (SSNHL). Conclusion: Pure tone audiometry is cost effective and easy to perform. Early diagnosis and timely intervention will reduce the morbidity of deafness in our country. Hence it is necessary to identify and treat sudden sensorineural hearing loss and noise induced hearing loss at an early stage.
\end{abstract}

\section{Keywords}

Pure Tone Audiogram, Conductive Deafness, Sudden Sensorineural Hearing Loss, Ototoxicity, Presbyacusis, Noise Induced Hearing Loss

\section{Introduction}

Hearing is an important and essential sense for verbal communication, language skills and personality development. Hearing loss is the second most common disability in India after the loco motor disability. More than 40 $\mathrm{dB}$ hearing impairment in patients above 15 years and more than $30 \mathrm{~dB}$ hearing impairment in patients below 14 years in the better ear are considered as hearing disability.

Hearing loss is classified as:

How to cite this paper: Balasubramanian, G.K., Thirunavukkarasu, R., Kalyanasundaram, R.B. and Narendran, G. (2015) Assessment of Hearing Status by Pure Tone Audiogram-An Institutional Study. International Journal of Otolaryngology and Head \& Neck Surgery, 4, 375-380. http://dx.doi.org/10.4236/ijohns.2015.45062 


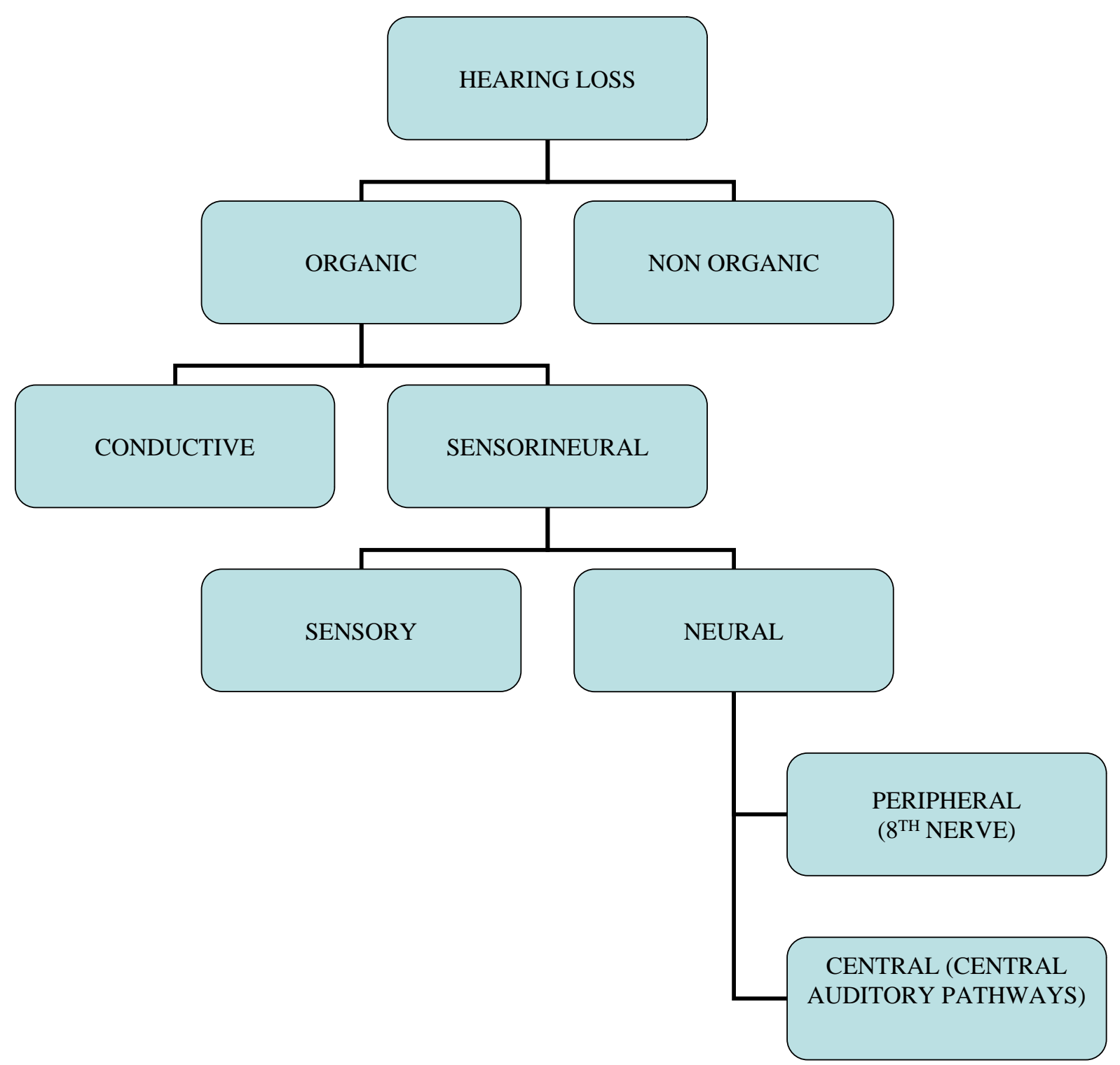

Conductive Hearing Loss: Any disease process which interferes with the conduction of sound to reach cochlea causes conductive hearing loss. The lesion may lie in the external ear, tympanic membrane, middle ear or ossicles up to stapedio-vestibular joint.

Sensorineural Hearing Loss: Results from lesions of the cochlea, $8^{\text {th }}$ nerve or central auditory pathways. It may be present at birth (congenital) or start later in life (acquired).

According to WHO census, around 360 million have hearing disability and the majorities are adults (91\%) and children are only 9\%. Prevalence of hearing loss is more in the age group above 65 years [1]. Our study shows that age group of 50 years and above are involved more in number than other age groups.

National Institute on Deafness and other Communication Disorders (NIDCD) states that 15\% of the population is having hearing loss due to loud noise in the working place or due to prolonged use of mobile phones [2]. Prolonged use of mobile phones for more than 30 minutes can cause $10 \mathrm{~dB}$ transient hearing loss [3]. As per the available information, about $6.3 \%$ of the Indian population is suffering from hearing impairment. Among these, the rural populations are more commonly affected than the urban population [4]. Hearing loss in children may affect their education due to the defective development of perceptual and linguistic abilities, because of reduced aural input [5]. Most common cause for hearing loss in children is serous otitis media or glue ear.

Sudden Sensorineural Hearing Loss (SSNHL) is defined as greater than $30 \mathrm{~dB}$ hearing impairment, over at 
least three contiguous frequencies, occurring over a period of 72 hours or less. Males are more commonly involved than females and the vulnerable age group is around 45 - 49 years. Presbyacusis or age related hearing loss is a slowly progressing one and involves both ears equally. Initially it affects the higher frequencies and later affects the lower frequencies also. The first sign is inability to understand the speech in noisy surrounding.

In pure tone audiogram, the tested frequency ranges from $250 \mathrm{~Hz}$ to $8000 \mathrm{~Hz}$, and hearing level from $-10 \mathrm{~dB}$ to $120 \mathrm{~dB}$. This test is both qualitative and quantitative (Type and Severity of hearing loss). The degree of deafness is classified based on WHO (1980) classification with reference to ISO: R.389-1970 (International Calibration of Audiometers) as follows:

$\begin{array}{ll}\text { Normal Hearing } & 0-25 \mathrm{~dB} \\ \text { Mild Hearing Impairment } & 26-40 \mathrm{~dB} \\ \text { Moderate Hearing Impairment } & 41-55 \mathrm{~dB} \\ \text { Moderately Severe Hearing Impairment } & 56-70 \mathrm{~dB} \\ \text { Severe Hearing Impairment } & 71-90 \mathrm{~dB} \\ \text { Profound Hearing Impairment } & >90 \mathrm{~dB}\end{array}$

\section{Aims and Objectives}

The aims and objectives are to assess the hearing level, the degree and type of deafness in patients attending the outpatient department.

\section{Materials and Methods}

This is a prospective study conducted in our institution. Patients who attended the Department of Otorhinolaryngology and Head and Neck Surgery OPD from Jan-Dec 2014 (about 1575 patients) were taken for study. The age of patients varied from 10 to 70 years. All patients were subjected to pure tone audiometry (MAICA-MA52) after an otorhinolaryngeal examination. Both air conduction and bone conduction were measured with Hughson Westlake technique modified by Carhart \& Jerger and plotted in graph. Most paediatric patients were subjected to tympanogram also. Male: Female ratio, age distribution, degree of deafness and type of deafness were evaluated.

\section{Results and Analysis}

Our study shows that $64 \%$ of males and $34 \%$ of females are involved. Among males, the 40 - 59 years age group is more commonly affected, this correlates with WHO data. Among females, the 20 - 39 years age group is more commonly affected (Table 1). Our study shows that 40 - 59 years age group is more commonly involved (38\%), 20 - 39 years age group constitutes $30 \%$, above 60 years constitutes $20 \%$ and the rest $12 \%$ is 10 - 19 years group.

This study reveals that $42 \%$ are suffering from sensorineural hearing impairment, $15 \%$ from conductive type, $14 \%$ shows mixed type and the rest $28 \%$ have normal hearing (Table 2).

In this study, about $29 \%$ have mild degree of deafness, $26 \%$ have moderate degree, $11 \%$ have severe degree, $6 \%$ suffer from profound to total deafness and the remaining $28 \%$ have normal hearing. Moderate degree of deafness is common above 40 years. In our study, profound and total deafness is evenly distributed in all age groups (Table 3).

\section{Discussion}

In our study the majority of patients belong to the male sex (64\%). Among the males, $4^{\text {th }}$ and $5^{\text {th }}$ decades are more vulnerable age groups. Around $28 \%$ of the cases are unilateral. Pure tone thresholds in females are lower at higher frequencies compared to males, suggesting that aging process begins earlier in men. Conductive hearing loss is more common in younger individuals and as the age advances sensorineural hearing loss predominates. The majority of subjects with hearing loss belong to working age group. This is probably due to occupational noise exposure, stress and trauma. Subjects working in industries are more vulnerable for noise induced hearing loss.

Tucker has argued that hearing is an ability that may be apprehended, thus screening for hearing at school entry level, especially for suspected unilateral mild to moderate hearing loss should be considered [5]. Robinovich 
Table 1. Sex distribution in different age groups.

\begin{tabular}{ccccc}
\hline Age Groups & Male & Female & Total & Percent \\
\hline $10-19$ years & 117 & 81 & 198 & $12 \%$ \\
$20-39$ years & 236 & 232 & 468 & $30 \%$ \\
$40-59$ years & 415 & 179 & 594 & $38 \%$ \\
60 years \&above & 244 & 71 & 315 & $20 \%$ \\
\hline
\end{tabular}

Table 2. Age wise distribution of type of hearing loss.

\begin{tabular}{cccccc}
\hline Age groups & Normal & Cond. HL & SN.HL & Mixed HL & Total \\
\hline 10 - 19 years & 81 & 63 & 34 & 20 & 198 \\
20 - 39 years & 177 & 121 & 108 & 62 & 468 \\
40 - 59 years & 180 & 54 & 282 & 78 & 594 \\
60 years \& above & 8 & 0 & 242 & 65 & 315 \\
\hline
\end{tabular}

Table 3. Age wise distribution of degree of hearing loss.

\begin{tabular}{ccccccc}
\hline Age groups & Normal & Mild HL & Moderate HL & Severe HL & Profound HL & Total \\
\hline $10-19$ yrs & 81 & 41 & 40 & 15 & 21 & 198 \\
$20-39$ yrs & 177 & 116 & 98 & 51 & 26 & 468 \\
$40-59$ yrs & 180 & 208 & 119 & 65 & 22 & 594 \\
60 \& above & 8 & 92 & 153 & 40 & 22 & 315 \\
\hline
\end{tabular}

has stated that early identification of hearing loss and adequate corrective measures help in better speech, language, social, psychological and educational development and a more satisfactory outcome [6].

More recently Dr. Frank Lin and his colleagues at Johns Hopkins University found a strong relationship between degree of hearing loss and risk of developing Dementia. Patients with mild degree have 2 times, moderate degree 3 times and severe degree has 5 times the risk than normal hearing individuals [7]. Hearing loss is an invisible handicap. Although it occurs in an increasing prevalence with age, hearing loss is often ignored during the diagnosis and treatment of cognitive and memory disorders in elderly patients.

Sudden sensorineural hearing loss is nowadays increasing in incidence. The causes may be infection, circulatory problems, meniere's disease, neoplasms, trauma, metabolic disorders, immunologic disorders or idiopathic. So in all cases of this type of hearing loss proper investigation regarding the etiology is very important. We did all relevant investigations and in many cases we found that viral infection is the culprit and some cases are idiopathic. The treatment includes systemic or oral steroids, hyperbaric oxygen therapy, antiviral drugs, vasodilators and chemorheologic agents. Most of the sudden sensorineural hearing loss patients presented with symptoms similar to eustachian tube catarrh. Because of this most patients presented with total hearing loss at the time of consultation. So in all cases of hard of hearing, audiological evaluation is mandatory and we have to do that at the first visit itself. Among all, pure tone audiometry is the most reliable, easy and cost effective method when compared to others.

Morbidity due to hearing loss in paediatric age group is inversely proportional to the literacy of parents. Most common causes for deafness in paediatric age group are Otitis Media with Effusion (OME), eustachian tube dysfunction, chronic suppurative otitis media and acute otitis media. For all these cases infection plays a major role, and it is more prevalent in low socioeconomic status and families with illiteracy. Infection is the most common cause for hearing loss in developing countries according to WHO data [8].

Tharwat and his colleagues, 1998, and Arts and others, 2002, stated that cochlear implants are needed for those patients with bilateral profound to total hearing loss who could not be benefitted with formal hearing aids and it is recommended especially in the younger age group [9]. 
In our study, most of the paediatric age group patients suffered from conductive type of deafness. Most common etiology for this is Otitis Media with Effusion. Pneumatic otoscopy is the diagnostic tool for this OME, but Tympanometry is the gold standard. Hence all those patients were subjected to impedence audiometry. Most of them were found to have Glue ear and received treatment and recovered completely. Treatment includes both medical and surgical management in the form of myringotomy and grommet insertion. Conductive type of hearing loss in adults are due to chronic suppurative otitis media and these are managed by mastoidectomy, if there is no improvement after the clearance of septic foci and medical management.

Auditory Neuropathy Spectrum Disorder (ANSD) is a type of hearing disorder in which the pure tone audiogram shows near normal hearing to profound hearing loss. But these groups can be confirmed by other tests, such as Oto Acoustic Emission (OAE) and Cochlear Microphonics (CM) which shows normal response and the Auditory Brain-Stem Response (ABSR) which shows abnormal or absent response. The site of lesion for this type of disorder is probably the inner hair cells of cochlea, spiral ganglia and the auditory nerve. Hyperbilirubinemia, anoxia/hypoxia, prenatal/neonatal infections, immune disorders are possible risk factors for this disorder [10]. So a detailed evaluation of antenatal, natal and postnatal history is important to identify this spectrum of disorders.

Noise induced hearing loss caused by exposure to recreational and occupational noise results in devastating disability that is virtually 100 percent preventable. This is the second most common form of sensorineural hearing deficit, after presbyacusis. Here the excessive sounds damage the stereocilia of the outer hair cells, therefore it is due to excessive wear and tear of delicate inner ear structures. Concurrent exposure to ototoxic drugs plays an additive effect. In olden days it was called as Boilermaker's disease. This type of hearing problems can be prevented by using earplugs or earmuffs. Noise induced hearing loss begins at higher frequencies (3000 - 6000 $\mathrm{Hz}$ ) and produce bilateral symmetrical loss [11].

\section{Conclusions}

Pure tone audiometry is a simple and accurate method for the diagnosis of hearing impairment. Deafness prevention can be done only by mutual cooperation of both medical and non medical personnel. Majority of patients belong to the working age group. Hence early identification with timely intervention can reduce the morbidity of deafness in this age group which in turn helps to improve the productivity of the nation.

Hearing impairment leads to social isolation in elderly persons. An early and adequate diagnosis has an important role in adapting sound amplification devices and rehabilitation procedures for auditory function in elderly. In paediatric age groups, cochlear implant is possible if deafness is identified in the early stage. This in turn helps to improve their language and social and personality skills.

\section{References}

[1] Taneja, M.K. (2014) Deafness a Social Stigma: Physician Perspective. Indian Journal of Otolaryngology and Head \& Neck Surgery, 66, 353-358.

[2] Health Info Statistics and Epidemiology. Quick Statistics, National Institute on Deafness and other Communication Disorders (NIDCD). http://www.nidcd.nih.gov/health/statistics/pages/quick.aspx

[3] Ramya, C.S., Karthiyanee, K. and Vinutha, S. (2011) Effect of Mobile Phone Usage on Hearing Threshold: A Pilot Study. Indian Journal of Otology, 17, 159-161. http://dx.doi.org/10.4103/0971-7749.94494

[4] National Programme for Prevention and Control of Deafness (NPPCD) Operational Guideline. http://mohfw.nic.in

[5] Tucker, S.M. (1995) Triagem e tratamento da surdez na pratica clinica. Anais Nestle, 50, 18-24.

[6] Nogueria, J.C.R. and da Conceicao Mendonca, M. (2011) Assessment of Hearing in a Municipal Public School Student Population. Brazilian Journal of Otorhinolaryngology, 77 (6).

[7] Lin, F.R., Metter, E.J., O’Brien, J.R., Resnick, S.M., Zonderman, A.B. and Ferrucci, L. (2011) Hearing Loss and Incidence of Dementia. Archives of Neurology, 68, 214-220. http://dx.doi.org/10.1001/archneurol.2010.362

[8] (2003) Prevention and Control of Deafness and Hearing Impairment Report on Intercountry Consultation, Colombo, Sri Lanka. World Health Organisation, Regional Office of South East Asia Report.

[9] Arts, H., Garber, A. and Zwolen, A. (2002) Cochlear Implants in Young Children. Otolaryngologic Clinics of North America, 35, 925-942. http://dx.doi.org/10.1016/S0030-6665(02)00059-2

[10] Vignesh, S.S., Jaya, V. and Muraleedharan, A. (2014) Prevalence and Audiological Characteristics of Auditory Neu- 
ropathy Spectrum Disorder in Paediatric Population: A Retrospective Study. Indian Journal of Otolaryngology and Head and Neck Surgery, 66 (3).

[11] Rabinowitz, P.M. (2000) Noise-Induced Hearing Loss Yale University School of Medicine, New Haven, Connecticut. American Family Physician, 61, 2749-2756. 